Proceedings of XIX International Scientific Conference "New Technologies and Achievements in Metallurgy, Material Engineering, Production Engineering and Physics", Częstochowa, Poland, June 7-8, 2018

\title{
Phase Structure and Heating Efficiency of As-Synthesised Iron-Oxide Nanoparticles and after Long Time Storage in Glycerol
}

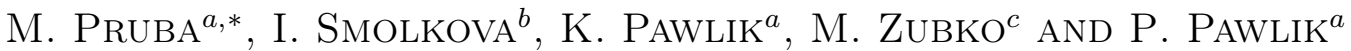 \\ ${ }^{a}$ Institute of Physics, Częstochowa University of Technology, al. Armii Krajowej 19, 42-200 Częstochowa, Poland \\ ${ }^{b}$ Polimer Centre, Faculty of Technology, Tomas Bata University in Zlin, Zlin, Czech Republic \\ ${ }^{c}$ Institute of Materials Science, University of Silesia, Katowice, Poland
}

\begin{abstract}
In the present work the structural characteristics and heating efficiencies of iron-oxide nanoparticles were studied. The investigated samples were produced by co-precipitation of $\mathrm{Fe}-\mathrm{O}$ nanoparticles from mixture of $\mathrm{Fe}^{2+}$ and $\mathrm{Fe}^{3+}$ salts in the alkaline environment. Furthermore, the influence of processing route and storage environment on the phase structure and heating efficiency was studies for glycol dispersed nanoparticles. The heating efficiency experiments were performed on $5 \mathrm{wt} \%$ glycerol dispersions of $\mathrm{Fe}-\mathrm{O}$ nanoparticles. The measurements were carried out on specimens directly after precipitation and for those kept in glycerol for substantial period of time in order to determine how the storage environment can impact their performance as a heating medium. Furthermore, comparative studies for nanoparticles produced at different processing routes were performed. The structural studies were carried out using X-ray diffractometry and transmission electron microscopy. The heating efficiencies and specific loss powers were determined using the self-constructed setup operating in the alternating magnetic field of various amplitudes from 2 to $4 \mathrm{kA} / \mathrm{m}$ and frequency of $100 \mathrm{kHz}$.
\end{abstract}

DOI: 10.12693/APhysPolA.135.229

PACS/topics: 75.47.Lx, 75.50.-y, 78.67.Bf, 78.70.Ck

\section{Introduction}

Almost all cells in the human body may degenerate and create a tumor. Currently, classical methods of dealing with cancer are based on surgical removal of the tumor, as well as on chemotherapy and radiotherapy [1]. Up to now it is impossible to consider modern cancer treatments without adjuvant therapies. The mechanism of these cancer treatments mainly consists of stimulation of the immune system in order to inhibit growth and impair the deformed cells. One of such adjuvant therapies is the magnetic hyperthermia [2]. In this method the magnetic nanoparticles introduced to the human system are subjected to radio-frequency external magnetic field. This causes a heat release that has detrimental effect on the cancer cell structure. In this therapy magnetite nanoparticles are commonly used. This material is approved by medical institutions for use in various medical treatments [3, 4]. Experimental research is currently focused on finding appropriate magnetic nanoparticles and magnetic field parameters, which would lead to the greatest possible heating efficiency. This would allow to minimize amount of nanoparticles introduced to the human system to achieve the same heating effect. In the present work, the synthesis and physical characteristics of magnetic nanoparticles are presented. In our studies the magnetite nanoparticles obtained using co-precipitation

*corresponding author; e-mail: mpruba@wip.pcz.pl process were used [5]. The main advantage of this method is relatively low cost of process, as well as possibility of tailoring the $\mathrm{Fe}_{3} \mathrm{O}_{4}$ crystallite sizes by the change of processing parameters. The heating efficiency of nanoparticle dispersions is characterized by the heating rates $(\mathrm{d} T / \mathrm{d} t)$ and specific loss power (SLP) $[3,6]$, that depend on the concentration of nanoparticles in the dispersion as well as on the measurement parameters (i.e. frequency and amplitude of external magnetic field). For this purpose it is rather difficult to compare results obtained in various labs. Therefore, in the present studies two different processing routes that were described in papers $[4,7]$, which led to obtain nanoparticles of various crystallite sizes were used. Furthermore, the phase constitution plays also an important role in the performance of nanoparticle dispersion. It is known that magnetite nanoparticles can transform to another form of ironoxides in water [8]. Therefore, in the present work the influence of long time (18 months) holding of nanoparticles in glycerol on the phase constitution of nanoparticles, as well as on the heating efficiency of their glycerol dispersion was studied.

\section{Samples preparation and experimental methods}

Two different co-precipitation routes were used to produce $\mathrm{Fe}_{3} \mathrm{O}_{4}$ nanoparticles: (i) method I (sample I) (described in [1]), using the solution of $\mathrm{FeCl}_{3} \cdot 6 \mathrm{H}_{2} \mathrm{O}$ and $\mathrm{FeSO}_{4} \cdot 7 \mathrm{H}_{2} \mathrm{O}$ salts with their molar ratio $\mathrm{Fe}^{2+}: \mathrm{Fe}^{3+}=$ 0.67 were precipitated under the $\mathrm{N}_{2}$ atmosphere at $60^{\circ} \mathrm{C}$. 
$\mathrm{NH}_{4} \mathrm{OH}$ solution was added dropwise under vigorous stirring; (ii) method II (sample II) — the reference sample - also prepared by co-precipitation from $\mathrm{FeCl}_{2} \cdot 4 \mathrm{H}_{2} \mathrm{O}$ and $\mathrm{FeCl}_{3} \cdot 6 \mathrm{H}_{2} \mathrm{O}$ salts with $\mathrm{NH}_{4} \mathrm{OH}$ solution as a precipitation agent. The process was carried out at $70^{\circ} \mathrm{C}$ under an Ar atmosphere. Details of the process were given in $[2,3,5]$. Furthermore, the $\mathrm{Fe}_{3} \mathrm{O}_{4}$ nanoparticles obtained by I method were kept in glycerol for 18 months to determine changes in their phase structure (sample III).

The phase structure of the samples was studied using Bruker D8 Advance X-ray diffractometer in the BraggBrentano configuration. The heating efficiencies of the magnetite nanoparticles dispersions in a glycerol and specific loss powers (SLP) were determined for dispersion of nanoparticles produced using both methods as well as for $\mathrm{Fe}_{3} \mathrm{O}_{4}$ sample kept in glycerol for 18 months. The details of self-constructed setup for measurements of heating efficiency of nanoparticle dispersions was widely described in [7].

\section{Results and discussion}

The X-ray diffraction patterns measured for all three samples, are presented in Fig. 1. For samples I and II, XRD analysis has shown presence of only one $\mathrm{Fe}_{3} \mathrm{O}_{4}$ phase. Results of further Rietveld refinement are collected in Table I. It was shown that volume weighted coherently diffracting domain sizes $L_{v o l}$ that are related to the crystallite sizes are of the order of $11 \mathrm{~nm}$ for sample I and III, while in case of sample II, the $L_{v o l}$ reaches $\approx 17 \mathrm{~nm}$. Furthermore, the nanoparticles kept in glycerol for 18 months (sample III) undergo significant phase transformation. Here aside from the magnetite component an additional diffraction peaks attributed to the $\mathrm{Fe}_{2} \mathrm{O}_{3}$ (hematite) were identified.

The TEM micrographs as well as crystallite size distribution measured for the sample I confirmed the results obtained from XRD analysis (Fig. 2). Furthermore, it was shown that only minor fraction of crystallites had their diameters larger than $18 \mathrm{~nm}$.

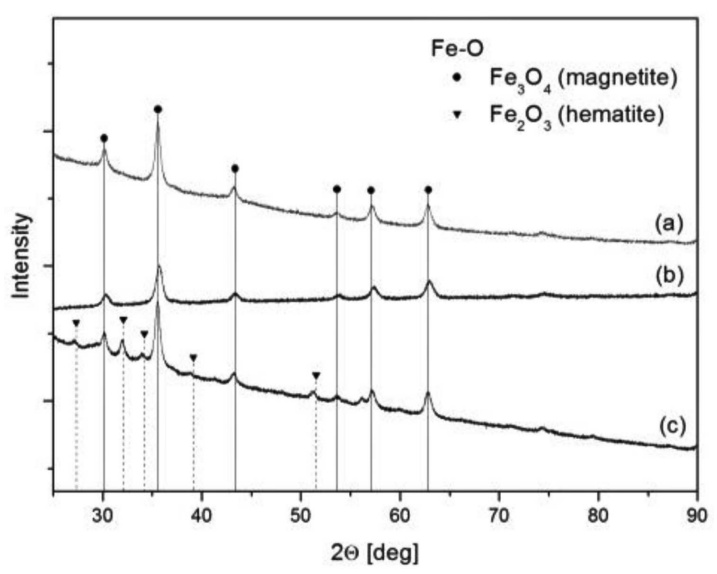

Fig. 1. XRD scans for sample I (a), sample II (b) and sample III (c).

\section{TABLE I}

Results of the Rietveld refinement; $L_{\mathrm{vol}}$ - volume weighted coherently diffracting domain sizes, $a$ - lattice constant, wt \% - weight percent of constituent phases.

\begin{tabular}{l|c|c|c|c|c|c}
\hline \hline $\begin{array}{c}\text { Phase name } \\
\text { (space group) }\end{array}$ & \multicolumn{3}{|c|}{$\begin{array}{c}\mathrm{Fe}_{3} \mathrm{O}_{4} \text { (magnetite) } \\
(F d-3 m)\end{array}$} & \multicolumn{3}{|c}{$\begin{array}{c}\mathrm{Fe}_{2} \mathrm{O}_{3} \text { (hematite) } \\
(R-3 c)\end{array}$} \\
\hline & $\begin{array}{c}a \\
{[\AA]}\end{array}$ & $\begin{array}{c}L_{\mathrm{vol}} \\
{[\mathrm{nm}]}\end{array}$ & {$[\mathrm{wt} \%]$} & $\begin{array}{c}a \\
{[\AA]}\end{array}$ & $\begin{array}{c}L_{\mathrm{vol}} \\
{[\mathrm{nm}]}\end{array}$ & {$[\mathrm{wt} \%]$} \\
\hline sample I & 8.36 & 10.8 & 100 & & & 0 \\
sample II & 8.35 & 16.8 & 100 & & & 0 \\
sample III & 8.37 & 11.2 & 45 & 5.27 & 12.1 & 55
\end{tabular}
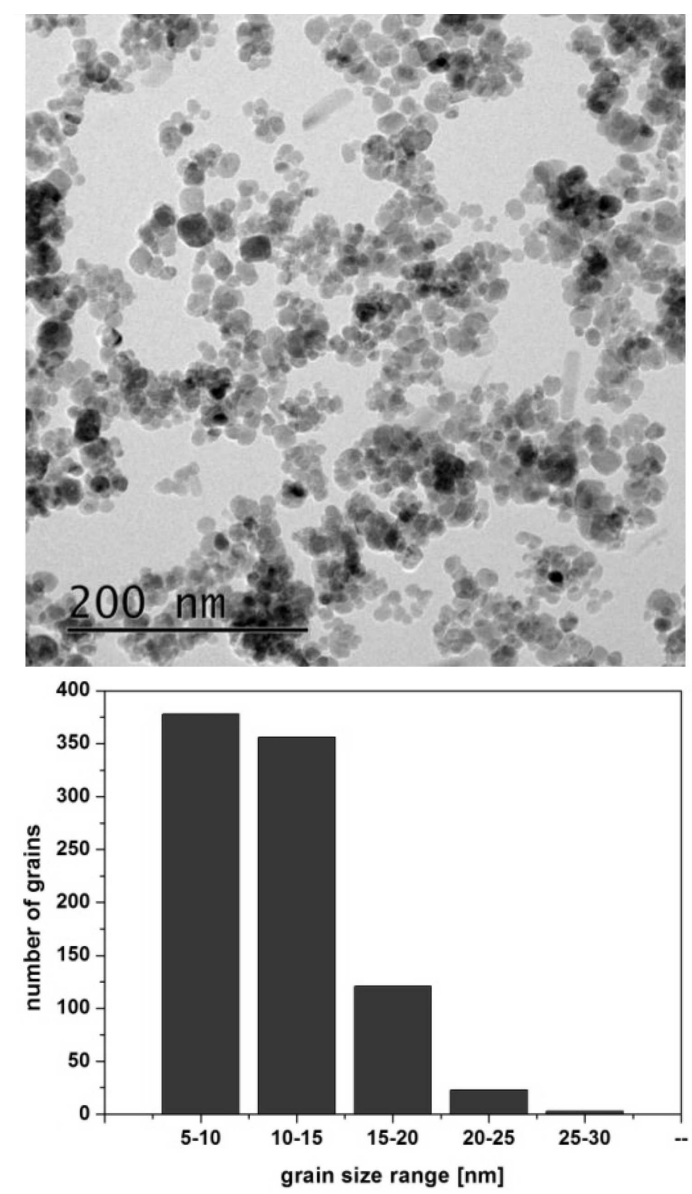

Fig. 2. The TEM image and grain size distribution for sample I.

For the investigated specimen the efficiencies of nanoparticle dispersions in glycerol subjected to $100 \mathrm{kHz}$ alternating magnetic fields $H$ were measured (Fig. 3). In Fig. 3a the comparison of heating rats measured for 5 wt\% dispersions of sample I and II in glycerol were presented. It has been shown that dispersion containing nanoparticles of smaller diameters (sample I) reveals higher heating rates than that for the larger nanoparticles (sample II) for the same values of magnetic field amplitudes. Heating rates $\mathrm{d} T / \mathrm{d} t$ and calculated specific loss powers SLP for various amplitudes of external magnetic fields $H$ are collected in Table II. 

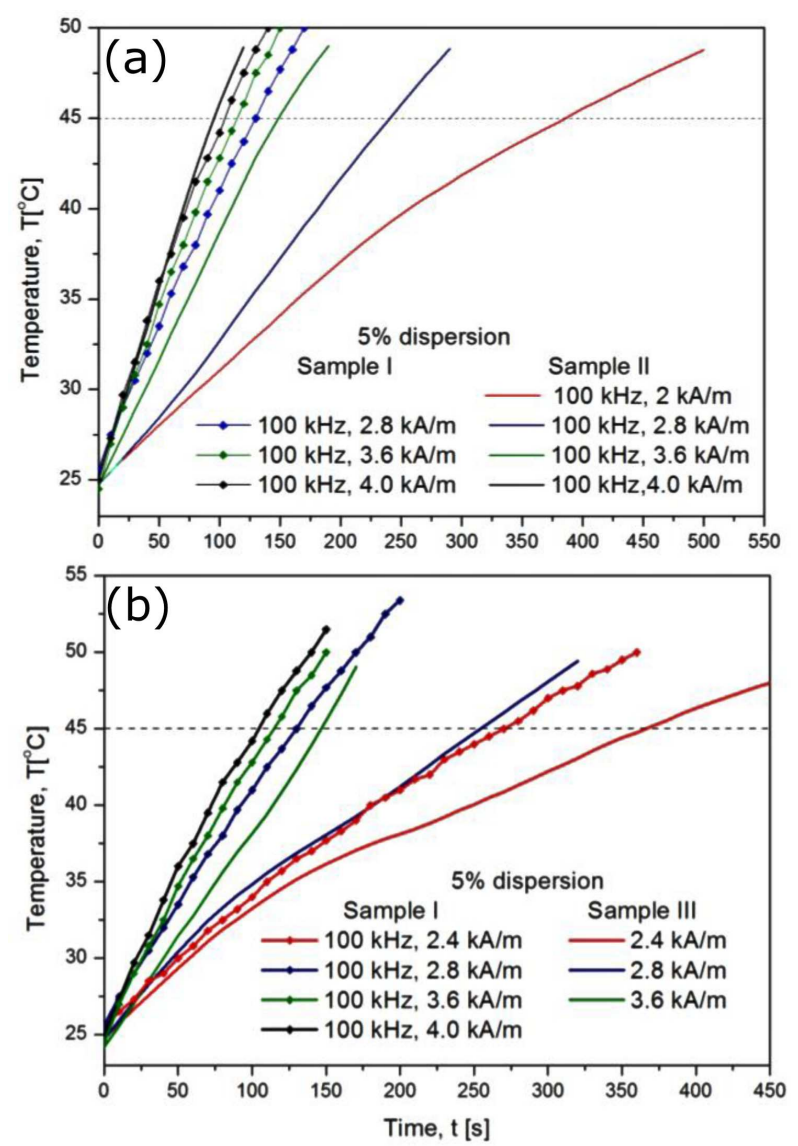

Fig. 3. Heating rates for $5 \mathrm{wt} \%$ dispersions of ironoxide nanoparticles in glycerol for a given amplitude of alternating external magnetic field: (a) comparison for sample I and II, (b) comparison for sample I and III.

TABLE II

Heating rates $\mathrm{d} T / \mathrm{d} t$ and calculated specific loss powers SLP obtained for $5 \mathrm{wt} \%$ dispersions of samples I, II and III subjected to $100 \mathrm{kHz}$ alternating magnetic fields $H$.

\begin{tabular}{c|c|c|c|c|c|c}
\hline \hline$H[\mathrm{kA} / \mathrm{m}]$ & \multicolumn{2}{|c|}{$\mathrm{d} T / \mathrm{d} t[\mathrm{~K} / \mathrm{min}]$} & \multicolumn{3}{c}{ SLP [W/g] } \\
\hline & I & II & III & I & II & III \\
\hline 2.8 & 10.0 & 7.8 & 4.6 & 9.4 & 6.2 & 4.2 \\
3.6 & 12.0 & 10.7 & 6.0 & 10.8 & 8.6 & 5.4 \\
4.0 & 12.6 & 12.3 & & 11.3 & 9.4 &
\end{tabular}

The comparison of $\mathrm{d} T / \mathrm{d} t$ for sample I and III are shown in Fig. 3b. It was revealed that the change of the phase constitution of nanoparticles has significant impact on their performance when subjected to $\mathrm{AC}$ magnetic field. A presence of hematite nanoparticles in sample III resulted in reduction of heating rates as well as SLP values. The heating efficiency parameters for sample III are also collected in Table III.

\section{Conclusions}

It was shown that a change of the parameters used in co-precipitation of magnetite nanoparticles results in their different crystallite sizes. This has also an impact on the heating efficiency of their dispersions when subjected to the alternating magnetic field. It was shown that change of co-precipitation parameters has no effect on the phase constitution of nanoparticles. In both cases the single phase magnetite nanoparticles were formed $[8,9]$. Furthermore, magnetite nanoparticles exposed to the glycerol environment for long time (18 months) undergo the phase transformation, resulting in formation of large fraction of hematite phase. This has also a detrimental effect on the heating efficiency of their dispersion due to lower magnetization of hematite in comparison to the magnetite phase.

\section{References}

[1] B.N. Ames, L. Swirsky Gold, Mutat. Res./Fundament. Mol. Mech. Mutagen. 447, 3 (2000).

[2] M. Izydorzak-Wozniak, M. Leonowicz, J. Nanosci. Nanotechnol. 14, 2258 (2014).

[3] S. Dutz, R. Hergt, Nanotechnology 25, 452001 (2014).

[4] A. Brezovich, in: Medical Physics Monograph, American Institute of Physics, New York 1988, p. 82.

[5] I.S. Smolkova, N.E. Kazantseva, H. Parmar, V. Babayan, P. Smolka, P. Saha, Mater. Chem. Phys. 155, 178 (2015).

[6] I. Smolkova, N. Kazantseva, V. Babayan, P. Smolka,. H. Parmar, J. Vilcakova, O. Schneeweiss, N. Pizurova, J. Magn. Magn. Mater. 374, 508 (2015).

[7] P. Pawlik, M. Pruba, K. Pawlik, K. Kotynia, Acta Phys. Pol. A 131, 1217 (2017).

[8] A. Jordan, P. Wust, H. Fahling, W. John, A. Hinz, R. Felix, Int. J. Hypertherm. 25, 499 (2009).

[9] A. Figuerola, R. Di Corato, L. Manna, T. Pellegrino, Pharmacol. Res. 62, 126 (2010). 